\title{
HERMANN SIMON: THE EDUCATION OF MANAGERS HAS TO BE VERY PRACTICAL
}

Prof. Dr. Dres. h.c. Hermann Simon is perceived as the second most influential thinker in the field of management in German speaking countries (after Peter Drucker). Prof. Simon is a successful academic, consultant and book author. He is the founder and CEO of Simon-Kucher \& Partners. This global consulting company is regarded as the world's leading pricing advisor. In an exclusive interview for CEBR, Prof. Simon talks about business education, the competences of managers, loyalty programs and other interesting topics.

You meet plenty of managers all over the world; who is the ideal manager? What are the crucial skills?

Managers need a whole set of competences. In recent years, two competences have become much more important. The first one is cultural openness, because managers in a globalized world are dealing with people - employees and customers - of many different cultures. The second important competence is integrity. One of the reasons for the crisis was that too many managers were playing with other people's money; they had asymmetric incentives, and eventually ruined companies. I would say that today, criteria like trustfulness and honesty are playing a bigger role than 20 years ago. So these are the most important changes in the requirements on managers.

Can you see any differences between "global" and Central European managers?

People are very entrepreneurial, in general more than in Germany; they are well educated, they are good at languages, and everybody speaks English. This is maybe a legacy from the Austro-Hungarian Empire, when you were supposed to speak at least five to ten languages (laughing). Seriously, I think that the managerial potential is the same as everywhere, but of course the experience is different because of the different historic development. German managers would probably have more international experience than Czech managers.

Our managers like to see themselves as more creative than others...

Concerning creativity, I think you are creative, but creativity in global competition means mostly hi-tech creativity. It is not only creativity you need in advertising campaigns, but it's also diligent work, spending money to develop superior solutions. Now, let me show a numerical example concerning European patents. In 2010, in Europe, the European Patent Office awarded about 50000 patents. Out of these 50000 patents, 12500 were from Germany. Czech Republic had 45 patents. Many countries ranked worse; for example, Greece, Portugal, Spain... But it shows an interesting fact, that there is an extreme discrepancy between Czech and German export and innovation activity (if I take the number of patents as a measure of innovation) and that export performance is independent of innovation. To return to the topic of the question, it reminds me of the period following the reunification of Germany, when we did seminars for the managers from former Eastern Germany. You cannot explain the principles of competition to somebody who doesn't know what market and competition mean. So there is some inevitable gap in the experience of managers even in Germany.

According to our surveys, most companies are driven by sales departments. Marketing has only second rate importance. This makes a parallel to a cashier in a shop, who thinks he is the most important person in the company. What is your opinion on the importance of marketing departments in companies?

The relative importance of marketing has changed. When we go back to the origins of marketing, to Philip Kotler, who I met recently in Bangladesh, they demand that the company should be led from the market, so marketing should become the most important function in the company. This opinion prevailed in the 60s, 70s, 80s, when marketing became more and more important, but I would say in the last 20 years, 
the importance of the role of marketing has been declining. It differs from country to country. In Germany, for instance, technical people are clearly dominating. Today, many companies are run by engineers. Finance is also more important than marketing in the UK and many other countries.

\section{Why did this happen?}

I think marketing is still perceived as extended advertising, and in my opinion, for example, marketing has never really incorporated sales, which is a very substantial function. When you look in the marketing literature, in the leading journals, there are so many articles on advertising, on market segmentation etc., but so few articles on sales. If you look at these articles, they are typically very theoretical. If you talk to the people from science, none of them read marketing journals. So

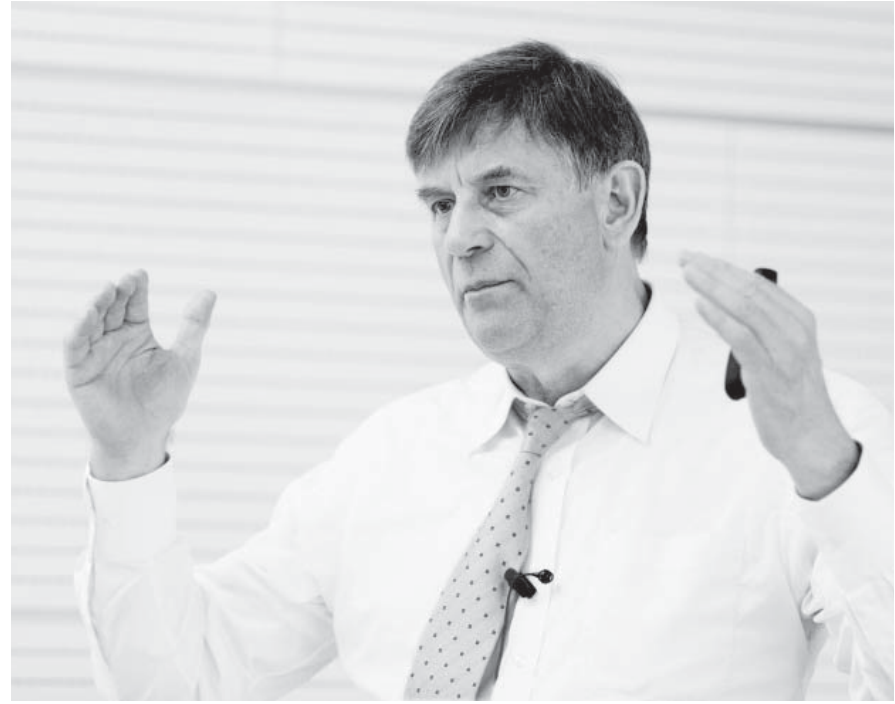

Photo by Jan Herch marketing has really failed to incorporate the wider context, to become of strategic importance; that's probably largely due to the academic discipline of marketing. I think sales is more difficult to analyze; you need a closer context, store data, advertising data and so on. So if marketing is to become more important, it has to become more holistic and comprehensive. I've talked to many successful CEOs who think that they succeeded not because of sales software systems, CRM systems etc., but because they paid extreme attention to the selection of their people. They even called their teachers and asked them about the competences and personality of the candidates. So the key factor of success was not marketing science, but good personal relationships. No marketing scientists would research these cases.

This might also be connected with education and the bridge between theory and practice. What is your opinion on how the cooperation of academics and practitioners should work?

I appreciate a good theoretical education. I would say that in economic education, the gap between what is being taught and what is useful in practice is not as large as in the area of science. I think that it is useful for students to go on internships and gain some practical experience; the true gap is in the knowledge, orientation and priorities of the teachers and professors. For instance, our company is focused on pricing; we are one of the largest pricing consulting companies in the world. So when I hire new people, I always ask them: "Do you know what price elasticity is?" Most of them would give a definition of price elasticity. Then I ask them how they apply this to a practical problem; most of them fail. What is obviously missing is the illustration of a theoretical definition on practical cases. Probably the professors

don't know themselves how to apply it (laughing). And that leads us back to the role, knowledge and experience of the educators. They just publish scientific articles, but don't care whether practitioners will be using the findings. I would say that between the academics and practitioners, there is no bridge, but a sea. Teachers and students should devote much more time to understanding what the practitioners need, how they do it, etc. When writing scientific articles, they should not only study the theory and literature, but begin with seeing the companies and talking with the managers. This approach, in my opinion, would lead to much better and usable results. But it does not happen, because it is not honored in the academic world.

\section{And from the point of view of the practitioners, managers, how can they be educated better?}

Well, I have some past experience with education of practitioners and managers, and I can say we used very few professors. In fact, educating managers who are already in management positions is quite difficult. I think that continuing education is very important, but it has to be very practical. Typically, business professors in Germany are often using case studies in education, but I am not fully convinced about their usefulness, since I think many of the case study teachers are rather perfect show stars.

\section{In the Central European region, managers often claim that they don't bother themselves with academic issues...}

I think that still you can get some useful information, but you have to do it right. For instance, going back to my pricing research, when I gave my first presentation for the 
practitioners about pricing, I was talking about price elasticity, price response functions, etc. Nowadays, no such words appear in my presentations. It's totally different. Fifteen years ago, before I explained the theory, curves etc., I gave them a simple exercise: an industrial product with a given price, given variable and fixed costs, a certain number of units sold, and I showed how the profit changes if the price or costs change. This trivial exercise occupies people for half an hour! I say I would never have shown that example during my academic years. Today, I am showing them all the time. The communication has to be simple, not theoretical. It is important to illustrate the theory with practical examples - what companies like Microsoft, McDonalds and BMW are doing, etc. Not many professors, according to my experience, master this. I don't use case studies, but on the other hand, I have a practical background, 25 years of consulting, which a professor would probably never have.

\section{Another topic of today is data in business. Business and customer intelligence are very popular; we often hear about the "amazonization" of consumers, where the information system is offering the consu- mers exactly what they might need. Massive loyalty schemes are based on this approach. Is this a way that marketing could become more important?}

There are some loyalty programs, which are very successful. Let me show you two examples. I bought the Bahnkarte 50 . This card costs $460 €$, but I have a 50\% discount on all tickets of Deutsche Bahn for one year. This is a loyalty scheme; once you pay for the card, you want to earn the money back. This is extremely efficient. Another successful program is the Lufthansa card, which gives me waiting line priority. I travel a lot, I often change planes, and this priority gives me a real value. There are some other programs of other firms, which offer real yearly discounts of only a few tens of euros, which is nothing and I don't use them. I would say that if a loyalty program has to be successful in the long-term, you have to offer real value, real advantages. The question is: does your business model allow that? For example, in the gasoline stations, the margins are so small that this is ridiculous.

Some programs know exactly what the people are buying and they can suggest you products that you "might need". And, in fact, they can propose what is mostly profitable for the reseller.

That was actually the second part of my answer concerning the "amazonization" of customers. I am a very regular customer of Amazon. I've never bought anything that Amazon suggested, but I buy everything that Amazon has and I want to have it. They know everything about what I have bought, but they don't know if I am a typical customer or not. They should differentiate. With Internet and customer cards, we have a new base of information, which allows us to better target markets, but I don't know how efficient the targeting measures are. I always hear from the marketers that the real value is the data they get with such a system. I don't disagree, but I don't agree. I don't know. I think that the customer is still the person who makes the decision and no Tesco, Amazon or whoever else makes the decision instead of the customer.

In our region it is easy to find experts in marketing communication and in branding, but in the field of pricing, it is a problem. Why do you think it's so? Is it the lack of demand of this service? Why is your company not here?

There is a simple reason why we are not yet here; we can only develop at most two or three offices per year. You need experienced people with language skills. Currently, we are going to open offices in Istanbul and Dubai, so two very fast growing regions. Concerning Central and Eastern Europe, we want to go to Moscow, but looking at the requirements and all these opportunities, indeed, Prague is not the highest priority. We want to have an office in Prague, but probably in six to seven years.

\section{If you have one day off, what would you do? What is your hobby?}

I don't have any specific hobbies. Because I grew up in a small village, and if I had a day off, I would go to my farmhouse. The house is old, but renovated and very convenient. If I had a free day with nice weather, I would get in my car and drive there, and I might drive our tractor across the fields, or go hiking or biking or things like that.

Authors

Tomáš Poucha

Marketing Institute

Faculty of Business Administration University of Economics, Prague Nám. W. Churchilla 4, 13067

Prague 3, Czech Republic tpoucha@mkti.cz

Tomáš Řička, Ph.D.

Department of Management Faculty of Business Administration University of Economics, Prague Nám. W. Churchilla 4, 13067

Prague 3, Czech Republic tomas.ricka@vse.cz 